\title{
SOBRE O ESTATUTO E A ESTRUTURA SINTÁTICA \\ DAS CONDICIONAIS FACTUAIS \\ DE SE DO PORTUGUÊS \\ DE MOÇAMBIQUE ${ }^{1}$
}

\section{SOBRE EL ESTATUTO Y LA ESTRUCTURA SINTÁCTICA DE LO SE FACTUAL CONDICIONAL DEL PORTUGUÉS DE MOZAMBIQUE}

\author{
ON THE SYNTACTIC STATUS AND STRUCTURE OF THE FACTUAL IF-CONDITIONALS OF \\ THE MOZAMBICAN PORTUGUESE
}

Víctor Mércia Justino*

Universidade Eduardo Mondlane

RESUMO: Este artigo discute o estatuto e a estrutura sintática das condicionais factuais de se do português de Moçambique. Os resultados da aplicação de testes sintáticos às factuais mostram que podem ser integradas ou periféricas. Deste modo, são distintas das factuais de outras línguas, como o inglês, que são consideradas apenas periféricas (HAEGEMAN, 2003; BHATT; PANCHEVA, 2006). Do ponto de vista estrutural, as integradas ocupam uma posição relativamente baixa que é a de adjunção a VP e as periféricas, pelo contrário, posições altas na frase, em adjunção a CP ou TP (HAEGEMAN, 2003; LOBO, 2003). Para darmos conta das integradas antepostas, com base em argumentos empíricos, defendemos que são geradas por Move do interior do TP da matriz, onde são geradas, para a posição de especificador de tópico, por topicalização da oração adverbial condicional, na linha de Duarte (1987, 1996) e Valmala (2009), contrariando a hipótese de que são geradas por Merge (LOBO, 2003; IATRIDOU, 1991).

PALAVRAS-CHAVE: Condicionais factuais. Estatuto sintático. Estrutura sintática. Português de Moçambique.

RESUMEN: En este artículo se analiza el estatuto y la estructura sintáctica de lo factual condicional del portugués de Mozambique (PM). Los resultados de la aplicación de pruebas sintácticas a los factuales muestran que pueden ser integradas o periféricas. De este modo, son distintas de las factuales de otros idiomas, como el inglés, que se consideran sólo periféricas (HAEGEMAN, 2003; BHATT; PANCHEVA, 2006). Desde el punto de vista estructural, las integradas ocupan una posición relativamente baja que es la de adjunción a VP y las periféricas, por el contrario, posiciones altas, en adjunta a CP o TP (HAEGEMAN, 2003; LOBO, 2003). Para dar cuenta de las integradas antepuestas, con base en argumentos empíricos, defendemos que son generadas por Move desde el interior del TP de la matriz, donde son generadas, para la posición de especificador de tópico, por topicalización de la oración adverbial condicional, en la línea de Duarte $(1987,1996)$ y Valmala (2009), contrariando la hipótesis de que son generadas por Merge (LOBO, 2003; IATRIDOU, 1991).

\footnotetext{
${ }^{1}$ Este trabalho é parte da minha tese de doutoramento (JUSTINO, 2018b), financiada pela Fundação Calouste Gulbenkian, que me concedeu a bolsa de estudos.

* Doutor em Linguística Portuguesa pela Universidade de Lisboa. É professor de Língua Portuguesa, Sintaxe e Linguística Descritiva do Português na Faculdade de Letras e Ciências Sociais da Universidade Eduardo Mondlane. E-mail: victormerciajustino@gmail.com
} 
PALABRAS CHAVE: Condicionales factuales. Estatuto sintáctico. Estructura sintáctica. Portugués de Mozambique.

ABSTRACT: This paper discusses the syntactic status and structure of the factual if-conditionals of the Mozambican Portuguese (MP). The results of the application of standard tests to distinguish between integrated and peripheral conditionals show that MP factual conditionals behave differently from those found in other languages because they may be integrated or peripheral, whereas for example in English, factual conditionals are always peripheral (HAEGEMAN, 2003; BHATT; PANCHEVA, 2006). Structurally, integrated conditionals are merged as VP adjuncts and typically surface in this relatively low position. Peripheral conditionals are merged higher in the clausal structure, as left or right adjuncts to CP or TP (HAEGEMAN, 2003; LOBO, 2003). It is argued that MP integrated $s e$-initial conditionals are generated by Move from the matrix TP where they are generated to Spec, TopP, by means of topicalization of the conditional adverbial clause, hence becoming se-initial conditionals. This is in line with Duarte (1987, 1996) and Valmala (2009), against the hypothesis that they are generated by Merge (LOBO, 2003; IATRIDOU, 1991).

KEYWORDS: Factual conditional. Syntactic status. Syntactic structure. Mozambican Portuguese.

\section{INTRODUÇÃO}

O Português de Moçambique (PM) é uma variedade do português falado, de acordo com os dados do Censo de 2007, por cerca de metade da população moçambicana, como L1 (10,7\%) ou como L2 (39,7\%) (CHIMBUTANE, 2012). Para além do português, que é a língua oficial, são faladas, em Moçambique, mais de vinte línguas bantu.

O presente artigo tem como objetivos aferir o estatuto sintático das condicionais factuais de se do PM e apresentar a estrutura sintática de cada tipo sintático de condicionais factuais.

Uma condicional é factual ou real quando a correlação entre a subordinada e a principal é dada como um facto (1); ou quando apenas a subordinada adverbial é que descreve um facto (2).

Se não vou correr nas manhãs, estou com um grupo de amigos. (JR41, JUSTINO, 2011)

a. Se nesse campo festivo que é o desporto rei marchamos para a violência, começo a pensar que estamos mais próximo de uma «Nação Pária par=2

b. Se o narciso é uma flor, então pertence ao reino vegetal. (PP)

As factuais como a de (1), correlativas de eventos ou situações (JUSTINO, 2018a, de acordo com Telmo Móia (c.p)), têm uma implicação temporal-aspetual particular, daí poderem ser parafraseáveis por quando ou sempre que:

(3) Quando/Sempre que não vou correr nas manhãs, estou com um grupo de amigos.

Por sua vez, os exemplos em (2) são de factuais episódicas. Nas factuais episódicas, o conector se pode comutar com os conectores factivos: como, já que, visto que, dado que ou afins (4).

(4) a. Já que/Como nesse campo festivo que é o desporto rei marchamos para a violência, começo a pensar que estamos mais próximo de uma «Nação Pária».

b. Já que/Como/Visto que o narciso é uma flor, pertence ao reino vegetal.

É de notar que, no grupo das episódicas, distinguem-se as genéricas das não genéricas. Ao contrário de (4a), não genérica, uma genérica é uma frase caracterizadora (4b). O antecedente desta condicional descreve propriedades reais, em todos os intervalos de tempo, de uma espécie de planta, “o narciso", ( 'os narcisos são sempre plantas e, como tal, pertentem ao reino vegetal'). 
Assim, este estudo toma como objeto os três subtipos de factuais: as correlativas de eventos/situações (1), as episódicas (2a) e as genéricas universais (2b).

Neste trabalho, os dados empíricos (condicionais factuais) foram obtidos através da combinação de métodos de pesquisa. Por um lado, os dados foram obtidos através da pesquisa de corpus em diferentes corpora eletrônicos do PM, nomeadamente o subcorpus Moçambique do $\mathrm{CRPC}^{2}$, o corpus Moçambula do projeto AC/DC ${ }^{3}$ e o corpus África ${ }^{4}$, e não eletrônicos, o corpus de Justino (2011), e, por outro, através de tarefas de produção provocada e juízos de gramaticalidade aplicadas a 25 sujeitos universitários moçambicanos ${ }^{5}$.

A descrição dos dados mostra que, no PM, há condicionais factuais integradas e periféricas. Do ponto de vista estrutural, as integradas ocupam uma posição relativamente baixa, que é a de adjunção a VP. Mas as integradas antepostas são derivadas por Move do interior do TP da matriz, onde são geradas, para a posição de especificador de tópico. As periféricas são adjuntas a posições altas na frase, CP ou TP, e são geradas por Merge externo, à direita ou à esquerda destas categorias funcionais.

O presente trabalho encontra-se estruturado como se segue: na secção 1 caracterizamos, descritivamente, a oposição condicionais integradas/condicionais periféricas; na secção 2, exploramos o estatuto sintático das condicionais factuais do PM; na secção 3, apresentamos, de forma esquemática, as estruturas sintáticas dessas condicionais. Finalmente, na secção 4, apresentamos as principais conclusões.

\section{OPOSIÇÃO CONDICIONAIS INTEGRADAS VS CONDICIONAIS PERIFÉRICAS}

Paralelamente à distinção que é feita para as orações subordinadas adverbiais em geral, em diferentes línguas (QUIRK et al., 1985; RENZI; SALVI, 1991; BOSQUE, DEMONTE, 1999; LOBO, 2003, 2013), as orações subordinadas adverbiais condicionais de se podem ser integradas (ou centrais) ou periféricas (HAEGEMAN, 2002, 2003, e.o). Essencialmente, as condicionais integradas distinguem-se das periféricas por manifestarem comportamentos diferentes em relação a fenómenos que envolvem o escopo ${ }^{6}:$ i) dependência do T(empo) da matriz, ii) resposta a interrogativas $Q u$-, iii) negação e operadores de foco, iv) estruturas clivadas, v) posição, vi) quantificadores e pronomes ligados, vii) lacunas parasitas, e viii) interrogativas e negativas alternativas (HAEGEMAN, 2002, 2003, 2004; LOBO 2003, 2013, e.o.).

Baseando-nos nestes fenómenos sintáticos, apresentamos de seguida, de um ponto de vista descritivo, a oposição sintática entre condicionais integradas e condicionais periféricas.

\subsection{ESCOPO DE T (OU DEPENDÊNCIA DE T MATRIZ)}

De acordo com Haegeman (2002, 2003), as orações condicionais integradas são temporalmente dependentes da oração matriz, no sentido em que a situação descrita na condicional toma como Ponto de Perspetiva Temporal (PPT) (KAMP; REYLE, 1993) o tempo

\footnotetext{
${ }^{2}$ Corpus de Referência do Português Contemporâneo disponível em: http://alfclul.clul.ul.pt/CQPweb/portugal/

${ }^{3}$ Acesso a Corpora / Disponibilização de Corpora, disponível em: https://www.linguateca.pt/CETEMPublico

${ }^{4}$ Disponível em: http://alfclul.clul.ul.pt/teitok/corpusafrica/index.php?action=cqpeact=advanced

${ }^{5}$ Para mais detalhes sobre os dados e metodologia de pesquisa, ver Justino (2018a, 2018b).

${ }^{6} \mathrm{O}$ efeito de escopo sugere que as integradas são dependentes da frase matriz, enquanto as periféricas são independentes da frase a que estão associadas (HAEGEMAN, 2002, 2003).
} 
da matriz (SILVANO, 2002; GONÇALVES; CUNHA; SILVANO, 2010). ${ }^{7}$ No exemplo (5), o Presente do Indicativo (cf. tire) tem obrigatoriamente uma referência temporal futura, que é determinada a partir do tempo da matriz (cf. will be).

If your back-supporting muscles tire (future), you will be at increased risk of lower-back pain. (HAEGEMAN, 2003, p. 320)

Com efeito, Haegeman (2003, p. 320) defende que, quando o tempo da subordinada está no escopo de T matriz, como em (5), é possível formar uma frase em que o operador if/se pode ser expandido para if and when/se e quando:

(6) If and when your back-supporting muscles tire, you will be at increased risk of lower-back pain.

As condicionais periféricas, pelo contrário, não são temporalmente subordinadas ao $\mathrm{T}$ da oração matriz, ou seja, a situação descrita na periférica não integra necessariamente o mesmo domínio temporal da situação matriz, podendo a sua localização temporal ser determinada a partir do tempo de enunciação (GONÇALVES et al., 2013). Isto é ilustrado em (7a), em que a referência temporal da periférica, no futuro, é distinta da que é expressa na matriz, e em (7b), em que a referência temporal da periférica, no presente, é a mesma da que é expressa na matriz. ${ }^{8}$

a. If I'm no longer going to be arrested for possessing cannabis for my own consumption [...], shouldn't I be able to grow my own? (HAEGEMAN, 2003, p. 321)

b. If we are so short of teachers, why don't we send our children to Germany to be educated? (HAEGEMAN, 2002, p. 124)

Assim, ao contrário do que acontece com as integradas (6), nas periféricas, não é possível expandir a frase subordinada para se e quando.

${ }^{\star}$ If and when we are so short of teachers, why don't we send our children to Germany to be educated? (HAEGEMAN, 2003, p. 321)

\subsection{ESCOPO DA NEGAÇÃO}

As condicionais integradas (9), mas não as periféricas (10), estão dentro do escopo da negação da frase matriz (cf. HAEGEMAN, 2003; LOBO, 2003, 2013). ${ }^{9}$ Eu não deixava de trabalhar se ganhasse a lotaria. (LOBO, 2003, p. 444) (= não era se ganhasse a lotaria que deixava de trabalhar; possível continuação: deixava se ficasse muito doente).

?Não podemos ficar descansados se o Zé já não mora aqui. (= só se o Zé está na prisão). (LOBO, 2003, p. 444)

\footnotetext{
${ }^{7}$ Na linha destes autores (GONÇALVES; CUNHA; SILVANO, 2010; SILVANO, 2002), a definição de dependência temporal articula os conceitos de PPT (KAMP; REYLE, 1993) - intervalo de tempo a partir do qual uma situação é perspectivada - e domínio temporal (DECLERK, 1991) - intervalo de tempo ocupado por uma situação ou conjunto de situações temporalmente relacionadas entre si através de formas verbais. Nesse sentido, a oração subordinada integrada e a frase matriz partilham o mesmo domínio temporal.

${ }^{8}$ Com dados como o de (7b) conclui-se que nem sempre que o tempo da encaixada e o da matriz coincidem se verifica dependência temporal, embora vários trabalhos tenham assumido, do ponto de vista sintático, que tal coincidência configura um caso de dependência temporal (AMBAR, 1992b; LANDAU, 2004, para as subordinadas completivas). Para uma discussão das limitações teóricas e empíricas desta aceção de tempos (in)dependentes, ver Duarte, Gonçalves e Santos (2012), Gonçalves et al. (2013) e Marques et al. (2015).

${ }^{9}$ Relativamente à frase (10), note-se que sem a continuação "só se o Zé está na prisão", a frase seria gramatical com a interpretação de condicional integrada. Mas, nesse caso, a presença do Zé seria condição para se ficar descansado e não o contrário. A continuação “só se o Zé está na prisão” força a leitura em que o Zé é um fator de insegurança e não de tranquilidade, ou seja, a leitura em que a oração condicional está fora do escopo da negação na matriz.
} 


\subsection{RESPOSTA A INTERROGATIVAS QU-}

As condicionais integradas podem ocorrer como resposta a interrogativas QU- (11).

(11) - Em que circunstâncias/condições é que o Zé compraria um carro novo?

- Se fosse aumentado. (LOBO, 2003, p. 152)

As periféricas, pelo contrário, nunca podem constituir-se como alvo de uma interrogativa QU- (12).

(12) - Em que circunstâncias/condições podemos ficar descansados?

- ${ }^{\star}$ ?Se o Zé já não mora aqui. (LOBO, 2003, p. 445)

\subsection{FOCALIZAÇÃO COM 'SÓ’ OU 'APENAS’}

Nas condicionais integradas, um marcador de foco exclusivo (como only ou só/apenas) na oração matriz tem escopo sob a subordinada condicional (13a), enquanto, nas periféricas, o marcador de foco na matriz não tem escopo sob a oração encaixada (13b) (LOBO, 2002, 2013).

(13) a. Eu só deixava de trabalhar se ganhasse a lotaria (= era só se ganhasse a lotaria que eu deixava de trabalhar) (LOBO, 2013, p. 2034)

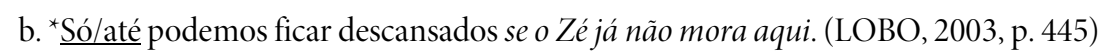

\subsection{CLIVAGEM}

As condicionais integradas (14a), mas não as periféricas (14b), podem ser clivadas.

(14) Era se fosse aumentado que o Zé compraria um carro novo. (LOBO, 2003, p. 151)

b *É se o Zé já não mora aqui que podemos ficar descansados. (LOBO, 2003, p. 444)

\subsection{QUANTIFICADORES E PRONOMES LIGADOS}

As condicionais integradas (15a), mas não as periféricas (15b), podem estar sob o escopo de um quantificador na frase matriz.
a. No one will answer the phone if he thinks it's his supervisor. (HAEGEMAN, 2003, p. 323)
b. Why does no one answer the phone, if he probably thinks it's his supervisor? (HAEGEMAN, 2003, p. 323)

Na frase (15a), o pronome pessoal sujeito da subordinada tanto pode referir-se a uma entidade específica saliente no discurso como pode ser uma variável ligada pelo quantificador no one. De modo a explicar o contraste entre (15a) e (15b) quanto à possibilidade de o pronome ser ou não ligado pelo quantificador, Haegeman (2003) defende que, em (15a), o pronome na condicional integrada é c-comandado pelo DP sujeito da matriz. ${ }^{10} \mathrm{Na}$ frase (15b), o pronome pessoal tem uma referência independente, i.e., não é ligado pelo quantificador no one, por isso a subordinada não está no domínio de c-comando do sujeito da oração matriz.

\footnotetext{
${ }^{10}$ A definição de c-comando assumida pela autora é a seguinte: "I assume that bound pronouns must be c-commanded by their binder (SAFIR, 1984; HAIK, 1984; MAY, 1986; HORNSTEIN, 1984 ETC.). A c-commands B if A is a sister of a constituent dominating B." (HAEGEMAN, 2003, p. 323).
} 


\subsection{LACUNAS PARASITAS}

De acordo com Haegeman (2002, 2003), as condicionais integradas permitem legitimar lacunas parasitas (16a). Nas condicionais periféricas, pelo contrário, não são legítimas lacunas parasitas (16b).

(16) a. Este é $o$ homemi que se conhecesses $[\varnothing]_{\mathrm{i}}$ ias amar $[\varnothing]_{\mathrm{i}}$.

b. ${ }^{\star}$ Este é $o$ artigo $o_{\mathrm{i}}$ que eu vou receber $[\varnothing]_{\mathrm{i}}$ hoje se, como dizes, ele me enviou $[\varnothing]_{\mathrm{i}}$ ontem.

Relativamente a (16b), Haegeman (2003) considera que, uma vez que a periférica não está integrada na oração matriz, não há legitimação de lacunas parasitas. A condicional, contendo a lacuna parasita, e a matriz, contendo o vestígio, não formam um tipo de "predicado complexo", isto é, a subordinada condicional não constitui um evento complexo com a oração matriz (HAEGEMAN, 2002 ${ }^{11}$. Para (16a), considera-se "[...] that complex predicate formation is only possible if the predicate of the associated clause ccommands the constituent with which it composes and which contains the parasitic gap" (HAEGEMAN, 2002, p.135).

\subsection{POSIÇÃO}

Para Lobo (2013), as orações adverbiais integradas podem ocorrer em posição final sem marcação prosódica particular (17a), enquanto as periféricas só podem ocorrer em posição final se forem antecedidas de pausa ou quebra entoacional, a que corresponde geralmente uma vírgula na escrita (17b). ${ }^{12}$
a. O Zé compraria um carro novo se fosse aumentado. (LOBO, 2003, p. 151)
b. Podemos ficar descansados ${ }^{\star}(||)$ se o Zé já não mora aqui. (LOBO, 2003, p. 443)

\subsection{INTERROGATIVAS E NEGATIVAS ALTERNATIVAS}

As condicionais integradas podem ocorrer em estruturas interrogativas alternativas (18a) e em estruturas negativas alternativas (18b).

a. O Zé compraria um carro novo se fosse aumentado ou se lhe concedessem um empréstimo? (LOBO, 2003, p. 153)

b. O Zé não compraria um carro novo se fosse aumentado, mas sim se the concedessem um empréstimo. (LOBO, 2003, p. 153)

As condicionais periféricas, no entanto, não podem ocorrer em estruturas interrogativas alternativas (19a) nem em estruturas negativas alternativas (19b).

a. ${ }^{*}$ Podemos ficar descansados se o Zé já não mora aqui ou se a porta está fechada? (LOBO, 2003, p. 446)

b. ${ }^{\star N a ̃ o ~ p o d e m o s ~ f i c a r ~ d e s c a n s a d o s ~ s e ~ o ~ Z e ́ ~ j a ́ ~ n a ̃ o ~ m o r a ~ a q u i, ~ m a s ~ s i m ~ s e ~ a ~ p o r t a ~ e s t a ́ ~ f e c h a d a . ~}$ (LOBO, 2003, p. 446)

Neste trabalho, assumimos a oposição entre condicionais integradas e condicionais periféricas, consoante respondam de forma positiva ou negativa, respetivamente, aos testes sintáticos acima descritos.

\footnotetext{
${ }^{11}$ Esta definição de predicado complexo é uma definição particular, que nada tem a ver com os casos de reestruturação ou união de orações e que decorre do facto de a subordinada constituir um evento complexo com a matriz.

${ }^{12}$ Em relação às periféricas, veja-se também Haegeman (2004, p. 68): "Peripheral adverbial clauses are typically prosodically set off from the associated clause by comma intonation, usually signaled by a comma in writing. Sometimes, however, the peripheral adverbial clause is typographically set off as if it were an independent clause."
} 
No Quadro 1 apresentam-se os elencos dos diferentes testes e o modo como distinguem entre si os dois tipos de condicionais.

\begin{tabular}{|c|c|c|c|c|c|c|c|c|c|}
\hline & \multicolumn{9}{|c|}{ Testes Sintáticos } \\
\hline $\begin{array}{c}\text { Tipologia sintática } \\
\text { de } \\
\text { Condicionais }\end{array}$ & $\begin{array}{c}\text { Escopo de } \\
\mathrm{T}\end{array}$ & $\begin{array}{c}\text { Escopo da } \\
\text { neg. }\end{array}$ & $\begin{array}{l}\text { Resp. inter. } \\
\qquad u^{-}\end{array}$ & $\begin{array}{l}\text { Escopo de } \\
\text { op. de foc. }\end{array}$ & Cliva-gem & $\begin{array}{c}\text { Quant. e } \\
\text { pron. } \\
\text { ligados }\end{array}$ & $\begin{array}{l}\text { Lacuna } \\
\text { parasit. }\end{array}$ & $\begin{array}{l}\text { Inter. e neg. } \\
\text { altern. }\end{array}$ & $\begin{array}{c}\text { Posiç. } \\
\text { final sem } \\
\text { pausa }\end{array}$ \\
\hline Integradas & + & + & + & + & + & + & + & + & + \\
\hline Periféricas & - & - & - & - & - & - & - & - & - \\
\hline
\end{tabular}

Quadro 1: Sumário dos diferentes testes e do modo como distinguem os dois tipos de condicionais

\section{COMPORTAMENTO SINTÁTICO DAS CONDICIONAIS FACTUAIS DO PM}

Da leitura do trabalho de Haegeman (2003), conclui-se que existe uma articulação entre a tipologia semântica e a tipologia sintática das condicionais. A autora defende que as hipotéticas (que designa por premise-conditionals) são integradas e as factuais (que designa por event-conditionals) são periféricas. As condicionais contrafactuais não foram objeto de análise nesse estudo, mas Lobo (2003, 2013) defende que estas condicionais se comportam como adverbiais integradas: podem estar sob o escopo da negação matriz e de marcadores de foco; admitem a clivagem, podem ocorrer como resposta a interrogativas $Q U$ - e em interrogativas alternativas e negativas alternativas.

É partindo do pressuposto de que existe uma articulação entre a tipologia semântica e a sintática (integradas/periféricas) que passaremos a explorar o comportamento sintático das condicionais factuais do PM.

Conforme já referido, Justino (2018a) assume que as condicionais factuais podem distribuir-se em correlativas de eventos/situações (1), episódicas (2a) e genéricas universais (2b). Assim, na aplicação dos testes com vista a aferir o estatuto sintático das condicionais factuais, foram considerados estes três subtipos de condicionais.

Os resultados obtidos através da aplicação dos diferentes testes sintáticos às condicionais factuais do PM são resumidos no quadro a seguir:

\begin{tabular}{c|c|c|c|c|c|c|c|c|c} 
& \multicolumn{7}{c}{ Testes Sintáticos } \\
\hline $\begin{array}{c}\text { Subtipos de } \\
\text { factuais }\end{array}$ & $\begin{array}{c}\text { Escop. de } \\
\mathrm{T}\end{array}$ & $\begin{array}{c}\text { Escop. da } \\
\text { neg. }\end{array}$ & $\begin{array}{c}\text { Respo. } \\
\text { inter. } \\
\text { Qu- }\end{array}$ & $\begin{array}{c}\text { Escop. de } \\
\text { op. de foc. }\end{array}$ & Cliva-gem & $\begin{array}{c}\text { Quant. e } \\
\text { pron. } \\
\text { ligad. }\end{array}$ & $\begin{array}{c}\text { Lacun. } \\
\text { paras. }\end{array}$ & $\begin{array}{c}\text { Inter. e } \\
\text { neg. } \\
\text { altern. }\end{array}$ & $\begin{array}{c}\text { Pos. } \\
\text { final sem } \\
\text { pausa }\end{array}$ \\
\hline $\begin{array}{c}\text { Correlativas de } \\
\text { eventos }\end{array}$ & + & + & + & + & + & + & + & + & + \\
\hline $\begin{array}{c}\text { Genéricas } \\
\text { universais }\end{array}$ & - & - & - & - & - & - & - & - & - \\
\hline Episódicas & - & - & - & - & - & $-/+$ & - & - & - \\
\end{tabular}

Quadro 2: Comportamento sintático dos diferentes subtipos de orações condicionais factuais 
Estes resultados permitem fazer as seguintes generalizações:

As factuais correlativas de eventos/situações são integradas. Tal justifica-se por poderem ocorrer no escopo de T matriz (20), da negação matriz (21), de operadores de foco (22) e de quantificadores na frase matriz (23) - indicando que a subordinada condicional está no domínio de c-comando destes operadores - e ainda por poderem legitimar lacunas parasitas (24) e ocorrer em posição final sem pausa (25).

(20) Se a cabeça não funciona funciona, o corpo é que sofre).

(21) Não saíamos às $12 \mathrm{~h}$ se entravámos às 7. (= não era se entravámos às 7 que saímos às $12 \mathrm{~h}$; possível continuação: era se entrávamos às 5 que saíamos às

(22) Só saíamos às $12 \mathrm{~h}$ se entravámos às 7 . (= é só se entravámos às 7 que saíamos às $12 \mathrm{~h}$ )

(23) [Nenhum aluno $]_{i}$ saía às $12 \mathrm{~h}$ se pro $o_{i}$ entrava às 7 .

(24) a. Se (= sempre que) um casal não tem filhos, adopta-os.

b. O que é que, se um casal não tem $[\varnothing]_{i}$, adopta $[\varnothing]_{i}$ ?.

Os pais sempre tinha que dizer alguma coisa se as coisas não correr bem. (Corpus África)

As factuais genéricas universais são periféricas. Estas factuais escapam ao domínio de c-comando de operadores de foco $(26)^{13}$, de negação (27), de T matriz (28) e de quantificadores (29); bem como não legitimam lacunas parasitas (30) nem ocorrem em posição final sem pausa (31a) e mesmo com pausa, são melhores se tiverem obrigatoriamente uma entoação suspensiva ou uma prosódia que indique que a oração condicional está extraposta (31b).

(26) ??O narciso só pertence ao reino vegetal se é uma flor. (= é só se o narciso é uma flor que pertence ao reino vegetal) \#O narciso não pertence ao reino vegetal se é uma flor. (= não é se o narciso é uma flor que pertence ao reino vegetal)

${ }^{\star}$ Se e quando o narciso é uma flor, pertence ao reino vegetal.

*[Todo o narciso $]_{\mathrm{i}}$ pertence ao reino vegetal se pro $_{\mathrm{i}}$ é uma flor.

a. Se as andorinhas são pássaros, então voam.

a'. ${ }^{\star} O$ que $i$ é que se as andorinhas são $[\varnothing]_{i},[\varnothing]_{i}$ voam.

a.” ${ }^{\star} O$ que $e_{i}$ que $[\varnothing]_{i}$ voam, se as andorinhas são $[\varnothing]_{i}$.

a. ??O narciso pertence ao reino vegetal se é uma flor.

b. O narciso pertence ao reino vegetal || se é uma flor.

${ }^{13}$ Nesse sentido, não podem ser clivadas: ?É (apenas) se o narciso é uma flor que pertence ao reino vegetal. 
As factuais episódicas são periféricas. Estas factuais ocorrem fora do escopo de T matriz (32), da negação (33), de marcadores de foco (34) e de quantificadores, na oração matriz (35); não são legítimas lacunas parasitas (36) nem sempre ocorrem em posição final sem pausa $(37)^{14}$.

^Se e quando os residentes da Vila de Boane sofrem restrições de água, então algo pode ter sucedido.

${ }^{\star}$ Como é que não lhe cortou se o branco chegou até aqui? (= não foi se o branco chegou até aqui que como é que lhe cortou?)

a. ${ }^{\star}$ Apenas/ só como é que lhe cortou se o branco não chegou até aqui?

b. *?Algo pode não ter sucedido se os residentes da Vila de Boane sofrem restrições de água.

Como é que [alguém $]_{i}$ pode desenvolver desta forma se $\operatorname{pro}_{\mathrm{i}}$ sofre com o seu próprio dinheiro?

a'. Se, como dizes, me enviaste o trabalho, vou vê-lo esta noite.

a'. ${ }^{\star}$ O que é que se, como dizes, me enviaste [Ø], vou ver [Ø] esta noite?

a. Começo a pensar que estamos próximo de uma «Nação Pária» se nesse campo festivo marchamos para a violência.

b. *É porque existe uma língua de que nós somos falantes se sabemos de tudo isso.

Assim, no grupo das condicionais factuais, podemos distinguir as factuais integradas das factuais periféricas. O comportamento semântico distinto das condicionais factuais favorece esta conclusão. Efetivamente, as factuais que classificámos como integradas modificam o evento descrito na matriz, o que se traduz numa maior coesão interfrásica. Isto é observado pelo facto de a subordinada constituir a causa direta do que é descrito na matriz (38):

a. Se falta chuva, morre-se de sede. Se vem, morre-se afogado. (= É por faltar a chuva que se morre de sede.../ Morre-se de sede. Isto acontece por causa de faltar chuva.).

b. Se a cabeça não funciona, o corpo é que sofre. ( $O$ facto de a cabeça não funcionar pode fazer com que o corpo é que sofra).

Quando a subordinada não constitui a causa direta (39), mas sim uma circunstância/razão que leva o falante a concluir ou dizer algo (40a), ou motivação para um ato de fala (40b) (QUIRK et al., 1985; LOPES, 2012), observa-se um escasso grau de integração sintática na matriz.

(39)

a. Se o narciso é uma flor, então pertence ao reino vegetal. (\#O facto de o narciso ser uma flor faz com que pertença ao reino vegetal.)

b. Se sabemos a língua portuguesa é porque a aprendemos na escola. ( $={ }^{*}$ Aprendemos na escola. Isto acontece por sabermos a língua portuguesa)

c. O branco, se não chegou até aqui como é que cortou ( ${ }^{\star}$ É por o branco não ter chegou até aqui que como é lhe que cortou?)

(40) a. Se o narciso é uma flor, então pertence ao reino vegetal. (= O narciso é uma flor, digo isto porque pertence ao reino vegetal.)

b. Se vocês os expulsaram, porque querem que nós vivamos com eles? (= Porque querem que nós vivamos com eles? E pergunto isto porque vocês os Expulsaram.)

\footnotetext{
${ }^{14}$ Factuais episódicas como a frase (37a) admitem ocorrer em posição final sem pausa porque podem adquirir a leitura hipotética (cf. Começo a pensar que estamos próximo de uma «Nação Pária» se nesse campo festivo marchamos (= marcharmos) para a violência.).
} 
O que acabámos de descrever está correlacionado com a distinção semântica entre condicionais de causa-efeito (ou de conteúdo) e condicionais de premissa-conclusão (dedutivas, epistémicas ou de ato de fala) (HAEGEMAN, 2002, 2003). A nosso ver, factuais integradas enquadram-se nas do tipo causa-efeito, como já demonstrado em (38), e as periféricas, no segundo tipo (cf. Se o narciso é uma flor, é porque pertence ao reino vegetal).

Além disso, há a considerar a afinidade (ou o paralelismo) semântico com outras construções adverbiais. Por exemplo, as factuais do tipo correlativo, que se comportam como adverbiais integradas, são equivalentes a temporais de quando, que, na literatura são classificadas como integradas (cf. HAEGEMAN, 2009; LOBO, 2003, 2013) (41). Por sua vez, algumas factuais que se comportam como periféricas são equivalentes às causais introduzidas por já que (42):

(41) a. Quando falta chuva, morre-se de sede.

b. Quando a cabeça não funciona, o corpo é que sofre.

(42) a. Já que o narciso é uma flor, então pertence ao reino vegetal.

b. Já que nesse campo festivo marchamos para a violência, começo a pensar que estamos mais próximo de uma «Nação Pária»

Na literatura, este tipo de causais (42) são caracterizadas como adverbiais periféricas (LOBO, 2001, 2003, 2013; LOPES, 2012; QUIRK et al., 1985).

Posto isto, concluímos que no PM as condicionais factuais podem ser integradas e periféricas, tal como acontece com as factuais do PE (JUSTINO, 2018b). São integradas as condicionais factuais correlativas de eventos e periféricas, as factuais genéricas e episódicas. Nesse sentido, são distintas das factuais de outras línguas, como o inglês, que são consideradas apenas periféricas (HAEGEMAN, 2003; BHATT; PANCHEVA, 2006).

Do ponto de vista estrutural, as factuais correlativas de eventos/situações, por estarem sob o escopo da negação matriz, de marcadores de foco, e de T matriz; e por poderem ser clivadas ou ocorrerem em posição final sem pausa ou quebra entoacional, ocuparão uma posição relativamente mais baixa na estrutura da frase, que pode ser a posição de adjunção a VP (cf., entre outros, HAEGEMAN, 2003; LOBO, 2003). As condicionais factuais genéricas universais e episódicas, pelo contrário, por não poderem estar sob o escopo da negação matriz e de operadores de foco; não poderem ser clivadas nem sempre poderem ocupar a posição final, só podem ser adjuntas a posições mais altas na estrutura da frase, CP ou TP.

\section{ESTRUTURA SINTÁTICA DAS CONDICIONAIS INTEGRADAS E PERIFÉRICAS FACTUAIS DO PM}

Na secção anterior, ficou definido que, no PM, existem duas classes sintáticas de adverbiais condicionais factuais: as integradas e as periféricas. Assim, nesta secção, vamos apresentar, de forma esquemática, as estruturas sintáticas dessas condicionais.

\subsection{CONDICIONAIS INTEGRADAS}

As condicionais integradas podem ocorrer à direita (43a) ou à esquerda (43b), em relação à frase matriz.

a. Os pais sempre tinha que dizer alguma coisa se as coisas não correr bem. (Corpus África)

b. Se não vou correr nas manhãs, estou com um grupo de amigos. (JR41, JUSTINO, 2011)

Para as condicionais integradas à direita, a configuração estrutural que assumimos é a que se segue em (44), em que a subordinada é adjunta a VP da oração matriz, na linha de trabalhos que adoptaram os mesmos critérios para definir uma oração adverbial integrada (HAEGEMAN, 2003, 2004, 2009; LOBO, 2003, 2006). 
(44) Estrutura sintática de uma condicional integrada à direita: Só haverá cheias se o nível chegar a $1500 \mathrm{~m}^{3}$ por segundo.

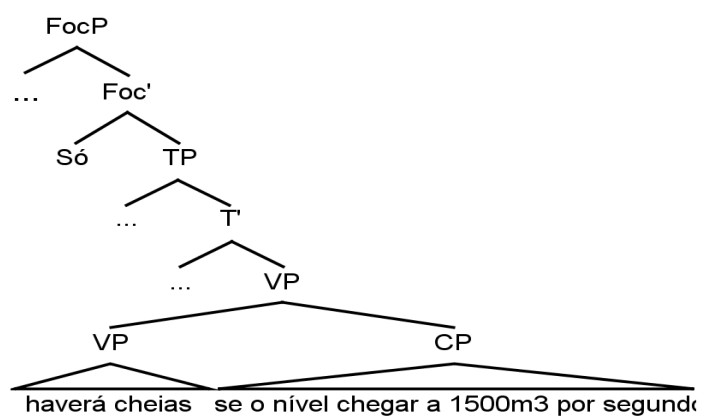

Esta configuração estrutural permite dar conta de, por exemplo, a oração adverbial integrada poder estar sob o escopo de advérbios de foco, da negação matriz, e do sujeito da matriz; isto é, estar no domínio de c-comando desses constituintes.

Para as adverbiais integradas à esquerda, propomos que se encontram numa posição alta relativamente à matriz, que aqui assumimos ser a posição de especificador de tópico, na linha da proposta adotada por outros autores, como Valmala (2009, p. 957).

(45) Exemplo de uma condicional adverbial integrada à esquerda: Se não vou correr nas manhãs, estou com um grupo de amigos.

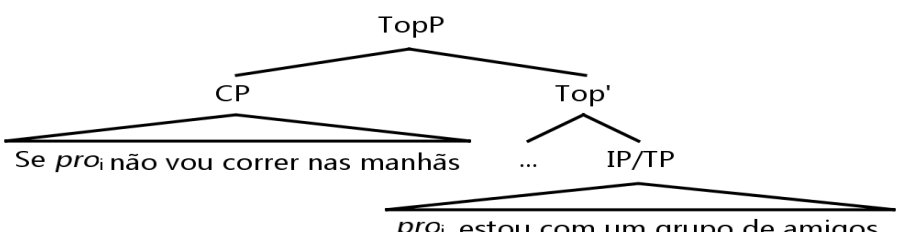

Por um lado, consideramos que as condicionais integradas antepostas são o tópico (43b) e (45), porque podem ocorrer em pares de pergunta-reposta como tópico da frase, o que é evidenciado quer pela posição à esquerda quer pelo facto de retomarem informação já introduzida na pergunta (AMBAR, 1992a; LOBO, 2003, 2013):

A: O que acontece se não vou correr nas manhãs?

B: Se não vou correr nas manhãs, estou com um grupo de amigos.

Além disso, ocorrerem em posição inicial seguidas de uma pausa (47) (VALMALA, 2009).

Por outro lado, a questão que se coloca é de saber se, em (45) (como por, e.g., Se não vou correr nas manhãs, estou com um grupo de amigos.), a adverbial integrada é gerada à esquerda por Merge externo, tal como é assumido por Lobo (2003), ou por Move, tal como se assume, para as condicionais de se, em Valmala (2009) e ainda para as condicionais integradas do PE por Justino (2018b). 
A hipótese de que a adverbial integrada condicional anteposta é gerada na base (LOBO, 2003) não permite dar conta do comportamento integrado destas condicionais independentemente de ocorrerem à direita ou à esquerda. Vimos que podem estar sob o escopo de T matriz, da negação, do sujeito, e de partículas de foco; são clivadas e constituem resposta a interrogativas $Q U$-. Este comportamento justifica que, na estrutura da frase, ocupam uma posição interna ao domínio do IP/TP, que é a posição de adjunção a VP, em forma lógica.

A hipótese da geração da condicional integrada na base à esquerda (48) não permite dar conta do facto de existir, nessas frases, uma interpretação de variável ligada do pronome da oração subordinada ainda que o pronome nulo, na adverbial, esteja fora do domínio de c-comando do operador de quantificação, nas frases em (48). Sabendo que a interpretação de variável ligada dos pronomes depende de uma relação estrutural específica, a relação de c-comando (REINHART, 1983), os dados em (48) serão plausivelmente explicados se considerarmos que na sua posição de base a adverbial se encontra no domínio de c-comando do operador de quantificação, conforme ilustrado em (49).

(48) a. Se pro $_{\mathrm{i}}$ entrava às 7 , nenhum aluno saia antes das $12 \mathrm{~h}$.

b. Se pro $_{\mathrm{i}}$ perde os últimos autocarros, qualquer um $_{\mathrm{i}}$ corre o risco de dormir fora de casa.

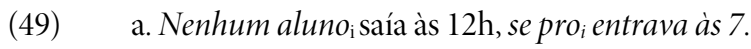

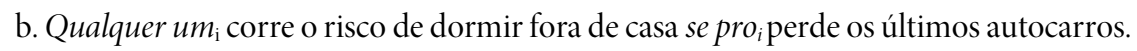

Assim, para dar conta das propriedades sintáticas que definem as condicionais integradas, assumimos que uma condicional adverbial factual integrada à esquerda é deslocada para a posição inicial, a partir da posição interna ao TP, conforme a configuração estrutural a seguir:

(50) Estrutura sintática de uma condicional integrada pré-verbal: se não vou correr nas manhãs, estou com um grupo de amigos.

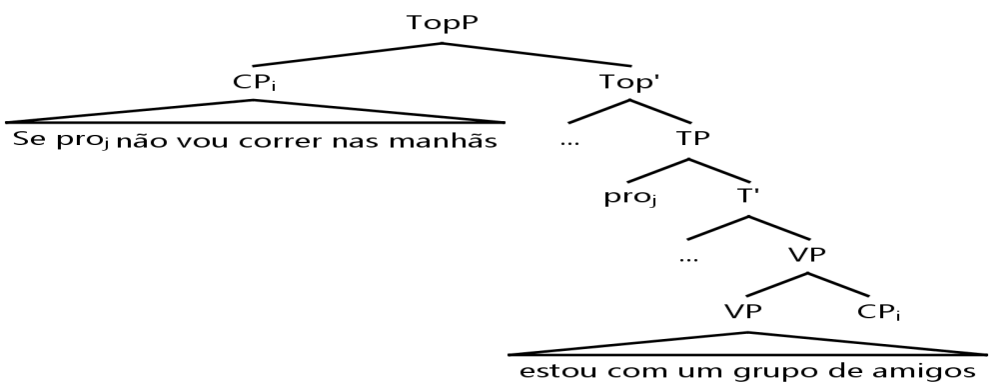

Adicionalmente, são argumentos a favor da hipótese de que, no PM, as factuais integradas à esquerda são geradas por movimento os que se seguem.

Em primeiro lugar, é possível uma leitura correferente entre um sujeito pleno (uma expressão-R) e o sujeito nulo da matriz: ${ }^{15}$

(51) a. pro i $_{\mathrm{i}}$ perde igualmente a sua validade se a carne for vendida ou distribuída aos empregados como forma de compensar o seu labor. par=2

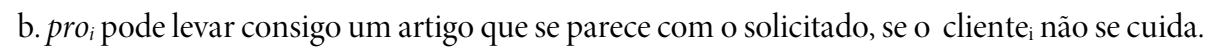

c. pro $_{i}$ expulsa-me do colégio na frescura do entardecer tal como Adão no Paraíso, se o padre descobrir a minha paixão.

\footnotetext{
${ }^{15}$ Os dados de (51) mostram a possibilidade de reconstrução com DP plenos no PM. Do ponto de vista do PE, a reconstrução, nestes contextos, viola o Princípio C da Teoria da Ligação. Porém, a violação do Princípio C que origina a agramaticalidade de exemplos como os de (51) no PE pode ser evitada através da topicalização da oração adverbial (cf. JUSTINO, 2018b, p.138, na linha de Biskup, 2006).
} 
A frase (51a) é extraída dos dados naturais (de corpora). As restantes foram adaptadas a partir de frases de corpora em que a adverbial se encontra à esquerda. Todas estas frases foram testadas com falantes do PM, que admitiram a leitura correferente entre os sujeitos. ${ }^{16}$

Em segundo lugar, no PM, as factuais integradas, enquanto constituintes que podem ser derivados por Move, podem reconstruir sob a negação na posição inicial (52a') ${ }^{17}$ :

$$
\begin{aligned}
& \text { a. Uma pessoa não é pobre se é casada. (= é pobre noutras circunstâncias) } \\
& \text { a'. Se a pessoa é casada, não é pobre. (= é pobre noutras circunstâncias) }
\end{aligned}
$$

Por fim, o movimento da adverbial integrada da posição interna ao domínio do IP, onde é gerado, para a periferia à esquerda (50) é suportada pela possibilidade de uma interpretação de sloppy identity do pronome possessivo que ocorre na elipse do VP de (51) (HAEGEMAN, 2003; VALMALA, 2009): ${ }^{18}$

Se o seu artigo foi aceite, $\mathrm{o}$ João vai à conferência e a Maria também vai. $([-] / \mathrm{VP}=[\mathrm{t}]$ à conferência se o seu artigo foi aceite).

a) A Maria vai à conferência se o artigo do João foi aceite. (strict reading)

b) A Maria vai à conferência se o artigo dela foi aceite. (sloppy reading)

A leitura sloppy mostra que a adverbial condicional está abaixo do TP do primeiro membro coordenado, daí ter sido apagada no segundo membro coordenado: (O João irá à conferência se o seu artigo for aceite e a Maria também irá à conferência se o seu artige for aceite).

\subsection{CONDICIONAIS PERIFÉRICAS}

As condicionais periféricas também podem ocorrer em posição final (54) ou em posição inicial (55).
a. Como é que podemos desenvolver desta forma se sofremos com o nosso dinheiro? par=1
b. Como é que iria justificar a gravidez se o meu marido nunca me forneceu a semente?(CRPC)

a. Se o narciso é uma flor, pertence ao reino vegetal.

b. Se sabemos a língua portuguesa é porque a aprendemos na escola.

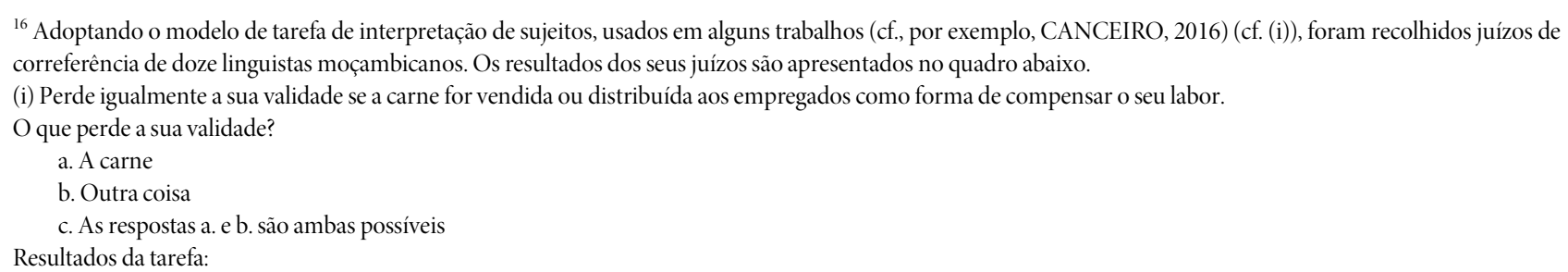

\begin{tabular}{c|c|c|c|c|c|c|c|c}
\multicolumn{3}{c|}{ Frase 51a } & \multicolumn{3}{c|}{ Frase 51b } & \multicolumn{3}{c}{ Frase 51c } \\
\hline $\begin{array}{c}\text { a. Leitura } \\
\text { Correfere. }\end{array}$ & $\begin{array}{c}\text { b. Leitura } \\
\text { Disjunta }\end{array}$ & $\begin{array}{c}\text { c. Leituras a.e } \\
\text { b. }\end{array}$ & $\begin{array}{c}\text { a. Leitura } \\
\text { Correfere. }\end{array}$ & $\begin{array}{c}\text { b. Leitura } \\
\text { Disjunta }\end{array}$ & $\begin{array}{c}\text { c. Leituras } \\
\text { a. e b. }\end{array}$ & $\begin{array}{c}\text { a. Leitura } \\
\text { Correfere. }\end{array}$ & $\begin{array}{c}\text { b.Leitura } \\
\text { Disjunta }\end{array}$ & $\begin{array}{c}\text { c. Leituras a. e } \\
\text { b. }\end{array}$ \\
\hline 7 & 1 & 4 & 7 & 3 & 2 & 10 & 0 & 2 \\
\end{tabular}

\footnotetext{
${ }^{17}$ Note-se que estas condicionais também admitem a reconstrução atualmente analisada em termos de cópia:

i. [Se pro $_{\mathrm{i}}$ não cumprir as suas promessas $]_{\mathrm{t}}$, Dhlakamaidemite-se [se pro $\mathrm{i}_{\mathrm{i} / \mathrm{j}}$ não cumprir as suas promessas $]_{\mathrm{t}}$.

ii. [Se pro $_{\mathrm{i}}$ se fizesse ao mar $]_{\mathrm{t}}$ não mais pro $_{i}$ voltaria a terra $\left[\text { se } \text { pro }_{\mathrm{i}} \text { se fizesse ao mar }\right]_{\mathrm{t}}$.

${ }^{18}$ Os exemplos são adaptados do inglês (cf. HAEGEMAN, 2003, p.324), por falta de exemplos com elipse do VP nos dados considerados.

i. If his paper is accepted, John will go to the conference and so will Mary.

a. Mary will go to the conference if John's paper is accepted.

b. Mary will go to the conference if her paper is accepted.
} 
Em certas periféricas, embora seja possível a adjunção à esquerda e à direita, parece que uma delas é a mais natural, ou seja, é menos marcada do que a outra. As condicionais de atos de fala, como as frases de (55), são preferencialmente periféricas à direita. Tal pode observar-se por nem sempre admitirem facilmente a ocorrência em posição inicial ${ }^{19}$ :

(56) a. ?Se sofremos com o nosso dinheiro, como é que podemos desenvolver desta forma?

b. ?Se o meu marido nunca me forneceu a semente, como é que iria justificar a gravidez?

c. Se o branco não chegou até aqui || como é que lhe cortou?

Ao contrário das periféricas de (56), as genéricas universais e episódicas de nexo dedutivo (55) são preferencialmente periféricas à esquerda (57), uma vez que não podem ocorrer em posição final sem ou com uma pausa.

a. ${ }^{\star} \mathrm{O}$ narciso pertence ao reino vegetal $(\|)$ se o narciso é uma flor.

b. ${ }^{*}$ É porque) a aprendemos na escola $(\|)$ se sabemos a língua portuguesa.

Assim, e pelo que ficou anteriormente exposto, para as periféricas à direita, exemplos como os de (54), a sua representação estrutural é a que se apresenta em (58). Já para as periféricas à esquerda, frases como as de (55), a sua representação estrutura é a que se apresenta em (57).

(58) Estrutura de uma condicional periférica à direita. Exemplo: Como é que vais beber se não tens chifre?

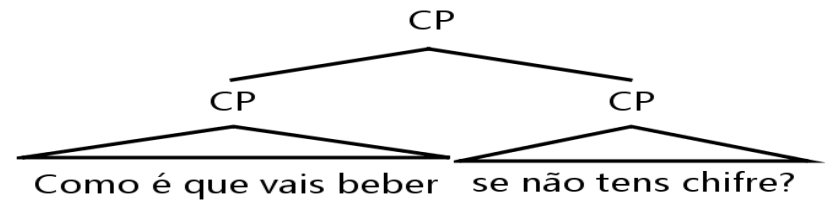

(59) Estrutura de uma condicional periférica à esquerda. Exemplo: Se o narciso é uma flor, pertence ao reino vegetal.

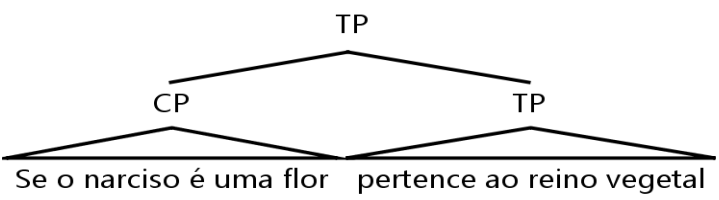

Em (58) e (59), assumimos que as periféricas, na estrutura da frase, encontram-se adjuntas à direita ou à esquerda de categorias funcionais altas, CP ou TP. Tal permite dar conta de a adverbial periférica estar geralmente fora do domínio de c-comando do sujeito da frase matriz:

(60) a. Como é que $[\text { o animal }]_{\mathrm{i}}$ vai beber se $\operatorname{pro}_{i} /$ ele $_{i}$ não tem chifres.

b. Se [o narciso $]_{i}$ é uma flor, pro $_{i}$ pertence ao reino vegetal.

\footnotetext{
${ }^{19}$ As periféricas que podem com facilidade ocorrer na posição inicial (56c) têm sempre uma pausa a separá-las da oração subordinada.
} 
Nas periféricas (60), os sujeitos das suas orações podem ser correferentes. No entanto, em nenhum dos casos há uma relação configuracional de c-comando do sujeito da matriz para com o sujeito da subordinada. Em (60a), sendo a oração matriz um CP, o seu sujeito não é nó irmão da subordinada que contém o sujeito pronominal. Em (60b), estando a subordinada adverbial adjunta à esquerda da matriz por Merge externo, o seu sujeito está sempre fora do domínio de c-comando do sujeito da matriz.

As estruturas sintáticas propostas para as periféricas permitem igualmente dar conta do facto de estas condicionais escaparem ao domínio de c-comando da negação matriz (61) e de marcadores de foco (62).

a. \#?Como é que não vais beber se tens chifres? (= vais beber noutras circunstâncias)

b. \#Se o narciso $o_{i}$ é uma flor, não pertence ao reino vegetal. (= pertence aoreino vegetal noutras circunstâncias)
a. ${ }^{\star}$ Apenas como é que vais beber se tens chifres.
b. \#Se o narciso $o_{i}$ uma flor, só pertence ao reino vegetal. (= é só se o narciso é uma flor que pertence ao reino vegetal)

Estes dados demonstram que os operadores de negação e de foco, na oração matriz, não têm escopo sobre a subordinada adverbial periférica à direita (cf. (61a) e (62a)), nem à esquerda (61b) e (62b). É de notar ainda que exemplos como o de (61b) apontam para as periféricas não reconstruírem sob a negação na posição inicial, sendo, deste modo, geradas por Merge externo e não por Move.

Outra propriedade que permite demonstrar que as periféricas são adjuntas a CP ou TP diz respeito à impossibilidade de legitimarem lacunas parasitas:
a. Como é que vou ver o trabalho se não mo enviaste?
a'. ${ }^{\star} O$ que $i$ é que como é que vou ver $[\varnothing]_{i}$ se não me enviaste $[\varnothing]_{i}$ ?

Seguindo Haegeman (2003), em (63), não são legítimas lacunas parasitas porque a adverbial contendo a lacuna parasita não é adjunta a VP da oração matriz.

Para terminar, refira-se que por não admitirem fenómenos que envolvem a focalização, como a clivagem, as periféricas têm inerentemente o traço [+ pressuposicional] e de informação conhecida (LOBO, 2001, 2003), ou seja, são tópicos. ${ }^{20}$ Repare-se que elas não podem constituir-se como resposta a interrogativas $Q u$ - enquanto foco informacional (64). Podem, no entanto, se antes forem interpretadas como um constituinte correspondente ao sintagma $Q U-$-, com a interpretação de tópicos (65).

$$
\begin{aligned}
& \text { - Em que circunstâncias é que o narciso pertence ao reino vegetal? } \\
& \text { - }{ }^{\star} \text { Pertence ao reino vegetal se é uma flor. } \\
& \text { - Em que circunstâncias é que o narciso pertence ao reino vegetal? } \\
& \text { - Se é uma flor, pertence... (não sei se noutras circunstâncias também pertencerá) }
\end{aligned}
$$

Em suma, as factuais periféricas podem ser adjuntas a CP ou TP tanto à esquerda como à direita. As factuais genéricas são preferencialmente periféricas à esquerda, enquanto as episódicas (de ato de fala ou de nexo dedutivo) são preferencialmente periféricas à direita.

\footnotetext{
${ }^{20}$ De acordo com Lobo (2003, p. 193), as orações adverbiais que têm inerentemente o traço [+ pressuposicional] serão sempre mapeadas/projectadas fora de TP.
} 


\section{CONCLUSÕES}

Neste trabalho, por um lado, aferimos o comportamento sintático das condicionais factuais do PM, e, por outro, apresentámos a estrutura sintática destas condicionais.

Os resultados da aplicação dos diferentes testes sintáticos às condicionais factuais permitem depreender que, nas factuais, há condicionais que se comportam como integradas e aquelas que que se comportam como periféricas. O estatuto integrado ou periférico parece estar correlacionado com o nível de dependência semântica entre as duas orações. Uma maior dependência semântica da adverbial relativamente à matriz corresponde à sintaxe das integradas, enquanto uma menor ou nenhuma relação semântica entre antecedente e consequente corresponde à sintaxe das periféricas. Por outro lado, estes resultados deixam em aberto a possibilidade de as condicionais do PM - e do PE (JUSTINO 2018b) serem distintas das condicionais de outras línguas, como o inglês, para as quais se defende que são apenas periféricas (cf. HAEGEMAN, 2003; BHATT, PANCHEVA, 2006), ainda que a análise de dados de corpora nestas línguas possa vir a revelar possibilidades não referidas na literatura.

Relativamente à estrutura sintática, assumimos que as integradas ocupam posições relativamente baixas na estrutura da frase que é a de adjunção a VP. No PE, Lobo (2003 e trabalhos subsequentes) defende que as integradas à esquerda são geradas por Merge externo, por, entre outras razões teóricas, Merge over Move e, empíricas, ausência de efeitos de reconstrução. Neste trabalho, e com base em argumentos empíricos, defendemos que as integradas antepostas são geradas por Move do interior do TP da matriz, onde são geradas, para a posição de especificador de tópico, por topicalização da oração adverbial condicional, na linha de Duarte (1987, 1996) e Valmala (2009).

As periféricas são adjuntas a posições altas na frase, $\mathrm{CP}$ ou TP, e são geradas por Merge à direita ou à esquerda destas categorias funcionais.

\section{REFERÊNCIAS}

AMBAR, M. Para uma sintaxe da inversão sujeito verbo em português. Colibri: Lisboa, 1992a.

AMBAR, M. Temps et structure de la phrase en portugais. In: OBENAUER, H; ZRIBI-HERTZ, A. (ed.). Structure de la phrase et théorie du liage. Saint-Denis: Presses Universitaires de Vincennes, 1992b. p. 29-49.

BHATT, R; PANCHEVA, R. Conditionals. In: EVERAERT. M., van RIEMSDIJK, H. (ed.). The blackwell companion to syntax. Blackwell, Boston e Oxford, v.1, p. 638-687, 2006.

BISKUP, P. Adjunction, Condition C, and the Background Adjunct Coreference Principle. In: BAUMER, D., MONTERO, D., SCANLON, M. (ed.). WCCFL, 25., 2006, Somerville. Proceedings [...]. Somerville, MA: Cascadilla Proceedings Project, 2006. p. $96-$ 104 .

BOSQUE, I; DEMONTE, V. Gramática descriptiva de la lengua española. Espasa Calpe: Madrid, 1999.

CANCEIRO, N. Relações referenciais entre sujeitos em estruturas coordenadas e subordinadas adverbiais em português europeu. 2016. 237f. Dissertação (Mestrado em Linguística) - Faculdade de Letras, Universidade de Lisboa, Lisboa, 2016.

Justino | Sobre o estatuto e a estrutura sintática das condicionais factuais de se do português de Moçambique 
CHImbutane, F. Panorama linguístico de Moçambique: Análise dos dados do III Recenseamento Geral da População e Habitação de 2007. Maputo, Moçambique: INE, 2012.

DECLERK, R. Tense in English: Its structure and use in discourse. Londres e Nova Iorque: Routledge, 1991.

DUARTE, I. A Construção de topicalização na gramática do português: regência, ligação e condições sobre movimento. 1987. Tese (Doutorado em Liguística) -Faculdade de Letras, Universidade de Lisboa, Lisboa, 1987.

DUARTE, I. Topicalização em português europeu: uma análise comparativa. In: DUARTE, I; LEIRIA I. (ed.). CONGRESSO INTERNACIONAL SOBRE O PORTUGUÊS, 1., 1996, Lisboa. Actas do [...]. Lisboa: APL/Edições Colibri, 1996. p. $327-360$.

DUARTE, I.; GONÇALVES, A.; SANTOS, A. L. Infinitivo flexionado, independência temporal e controlo. In: COSTA, A.; FLORES C.; ALEXANDRE, N. (ed.). Textos Selecionados do XXVII Encontro Nacional da Associação Portuguesa de Linguística. Lisboa: APL, 2012. p. 217-23.

GONÇALVES, A.; CUNHA, L. F.; SILVANO, P. Interpretação temporal dos domínios infinitivos na construção de reestruturação do português europeu. In: BRITO, A. M. et al. (ed.). Textos Selecionados do XXV Encontro Nacional da Associação Portuguesa de Linguística. Lisbon: APL, 2010. p. 435-447.

GONÇALVES, A. et al. Sequências de tempos em completivas finitas: restrições semânticas e efeitos na aquisição. In: Textos Selecionados do XXVIII Encontro Nacional da Associação Portuguesa de Linguística. Coimbra: APL, 2013. p. 433-452.

HAEGEMAN, L. Anchoring to speaker, adverbial clauses and the structure of CP. Georgetown University Working Papers in Theoretical Linguistics 2, 2002, p. 117-180.

HAEGEMAN, L. Conditional clauses: external and internal syntax. Mind and Language, v.4, n. 18, p. 317-339, 2003.

HAEGEMAN, L. The syntax of adverbial clauses and Its consequences for topicalisation. Antwerp Papers in Linguistics, n. 107, p. $61-90,2004$.

HAEGEMAN, L. The movement analysis of temporal adverbial clauses. English Language and Linguistics, n. 13, p. 385-408, 2009.

IATRIDOU, S. Topics in conditionals. 1991. 179 f. Tese (Doutorado) - PhD dissertation, M.I.T, Cambridge, 1991.

JUSTINO, V. A distribuição e a expressão gramatical do futuro do conjuntivo no Português de Moçambique. 2011. 178 f. Dissertação (Mestrado em Linguística) - Faculdade de Letras, Universidade de Lisboa, Lisboa, 2011.

JUSTINO, V. Tipologia semântica das condicionais no português de Moçambique. Revista da Associação Portuguesa de Linguística, n. 4, 2018a, p. 98-116. Disponível em: https://doi.org/10.26334/2183-9077/rapln4ano2018a35 . Acesso em: outubro 2018

JUSTINO, V. As Condicionais de 'se' no português de Moçambique e no português europeu. 2018b. Tese (Doutorado em Linguística Portuguesa) - Faculdade de Letras, Universidade de Lisboa, Lisboa, 2018b. 
KAMP, H.; REYLE, U. From discourse to logic. Dordrecht: Kluwer Academic Publishers, 1993.

LANDAU, I. The scale of finiteness and the calculus of control. Natural Language and Linguistic Theory, n. 22, p. 811-877, 2004.

LOBO, M. Para uma sintaxe das orações causais do português. Actas do XVI Encontro Nacional da Associação Portuguesa de Linguística. Lisboa: APL, 2001, p. 291-306.

LOBO, M. Aspectos da sintaxe das orações adverbiais do português. 2003. 452f. Tese (Doutorado em Linguística Portuguesa) Faculdade de Ciências Sociais e Humanas, Universidade Nova de Lisboa, Lisboa, 2003.

LOBO, M. Dependências temporais: a sintaxe das orações subordinadas gerundivas do Português. Veredas, Juiz de Fora, v. 10, n. 1 e 2, 2006. Disponível em http://www.ufjf.br/revistaveredas/files/2009/12/artigo055.pdf. Acesso em: maio 2015.

LOBO, M. Subordinação adverbial. In: RAPOSO et al. (ed.). Gramática do Português. Lisboa: Fundação Calouste Gulbenkian, 2013. p. 1879-2057.

LOPES, C. M. Contributos para o estudo de construções condicionais não canónicas no PEC. Diacrítica, Universidade do Minho, v. 23, n. 1, p. 149-170, 2009.

MARQUES, R. et al. Sequence of tenses in complementation structures: lexical restrictions and effects on language acquisition. In: KLASSEN, R.; LICERAS, J. M.; VALEBZUELA, E. (ed.). Hispanic Lingustics at the crossroads. theoretical linguistics, language acquisition and language contact. Amsterdam/Philadelphia: John Benjamins, 2015. p. 69-88. DOI: https://doi.org/10.1075/ihll.4.04mar.

QUIRK et al. A comprehensive grammar of the English language. London: Longman, 1985.

REINHART, T. Anaphora and semantic interpretation. Londres: Croom Helm, 1983.

RENZI, L; SALVI, G. (org.). Grande grammatica italiana di consultazione. II. I sintagmi verbale, aggettivale, avverbiale. Lasubordinazione. Bologna: il Mulino, 1991.

SILVANO, P. Sobre a semântica da sequência de tempos em português europeu. Análise das relações temporais em frases complexas com completivas. 2002. Dissertação (Mestrado) - Universidade do Minho, Braga, 2002.

VALMALA, V. On the position of central adverbial clauses. In: ASJU, 18., 2009, p. 951-970.

\section{()(1) $\circledast$}

Recebido em 20/09/2018. Aceito em 30/09/2018. 